\title{
Interculturalidad, inmigración y educación
}

Sebastián Sánchez Fernández

Catedrático de Didáctica y Organización Escolar

\section{Aclaraciones terminológicas y conceptuales}

Como punto de partida, es importante realizar algunas precisiones de tipo terminológico y conceptual en relación con temática de la diversidad cultural, dadas las implicaciones educativas que pueden tener algunas de las concepciones iniciales sobre la pluriculturalidad.

Existe un consenso pedagógico, bastante generalizado, desde el que se entiende que toda acción educativa debe intentar desarrollar positivamente todas las capacidades de los seres humanos, para que sean capaces de convivir en un inacabado juego de interacciones de derechos y obligaciones. Esta concepción de la educación supone que podamos distinguir entre educar, adoctrinar y adiestrar. Ya que en estos dos últimos casos, se desprecia, como mínimo, uno de los derechos fundamentales de toda persona: el derecho a la libertad $y$, consecuentemente se impide el desarrollo de la capacidad crítica, en especial, ante las mismas propuestas que se producen en el proceso de adoctrinamiento o adiestramiento.

Por lo tanto, si partimos de este concepto de educación, es fácil comprender que añadirle los adjetivos multi e intercultural nos lleva a una cierta redundancia, ya que toda educación sería, por definición, intercultural. Cualquier acción educativa tiene que procurar que los alumnos a los que pretende formar desarrollen capacidades que les permitan respetar la diversidad étnica y cultural y apreciar las aportaciones de todos los grupos, así como analizarlas críticamente junto con las propias. 
Entonces, podemos preguntarnos por qué utilizamos, incluso con cada vez más frecuencia y extensión, de un tiempo a esta parte, los términos multi e intercultural para caracterizar a la educación. En mi opinión, se hace, en la mayoría de los casos, para enfatizar una de vertientes sobre la que debe prestarse especial atención desde las actuaciones educativas: la formación en valores y actitudes encaminados a favorecer la comprensión, el respeto y la tolerancia positiva entre los miembros de todos los grupos étnicos y culturales, sin renunciar a las propias identidades individuales y colectivas. En otros casos, es cierto que también se produce un cierto esnobismo en el uso de estos términos, que suele conllevar una pérdida de su sentido profundamente educativo y una desnaturalización de sus importantes implicaciones para la práctica educativa y para las relaciones interpersonales y grupales.

En general, podemos valorar como positivo e incluso necesario el uso de estos términos como adjetivos de la educación, aunque sólo sea por una razón reivindicativa: el hecho de resaltar y reclamar esta faceta de la educación, imprescindible para cualquier práctica educativa de calidad.

También vale la pena plantearnos por qué venimos utilizando las palabras multi e interculturalidad de unos años acá, con intensidad creciente en diferentes esferas sociales y académicas (políticas, sociológicas, antropológicas, educativas, etc.) de nuestro país. si hace muchos más años que nos estamos moviendo en una zona del mundo especialmente influida por las relaciones interétnicas e interculturales.

Sin necesidad de remontarnos a períodos históricos demasiado lejanos, es fácil demostrar que la ubicación geopolítica de España -y, especialmente de as, Andalucía - ha posibilitado que, aunque hayan existido ciertas diferencias de grado según se trate de zonas rurales o urbanas, costeras o de interior, de mayor o menor riqueza, etc., se produzcan fenómenos relacionados con la multi e incluso con la interculturalidad. ¿Por qué, entonces, es a partir de los años 80 cuando se empiezan a utilizar estos términos y posteriormente a extenderse su uso?

A mi entender se han unido varios factores que han influido en este fenómeno. En primer lugar, la consolidación del sistema democrático como forma de gobierno ha conllevado la explicitación del respeto a la diversidad cultural como uno de los soportes fundamentales de nuestra Constitución de 1978. Ciertamente siempre ha existido en España un amplio abanico de culturas, con sus correspondientes manifestaciones, incluida la propia lengua, que han venido constituyendo lo que se suelen denominar minorías nacionales: principalmente vascos, catalanes y gallegos. Lo que hace la Constitución es valorar la diversidad cultural como enriquecimiento para todos y no como un problema. En consecuencia, conocer las diferentes culturas de nuestro país se convierte en una actividad muy apreciada y extendida entre la población. Hablar y escribir sobre ella pasa a ser uno de los temas prioritarios de los medios de comunicación social, lo que se extiende incluso a los mensajes publicitarios.

Por otro lado, desde siempre hemos contado en nuestro país - aunque con diferente distribución según regiones, provincias e incluso comarcas y localidades- con una minoría étnica, como son los gitanos. La importante aportación que, sin duda, supone este grupo 
a nuestra diversidad cultural, no suele valorarse como un enriquecimiento, a pesar de sus valiosas contribuciones en diferentes manifestaciones culturales, especialmente musicales y artísticas. Más bien se le suele percibir con una fuerte carga de estereotipos negativos, con tendencia a una identificación global como colectivo problemático.

Tenemos pues, desde hace tiempo, una evidente diversidad cultural distribuida por todos los rincones del país, junto con una minoría étnica claramente percibida e identificada, como fuentes de argumentación para ser conscientes de la multiculturalidad como fenómeno social y antropológico presente en nuestro país. En cambio, son los fenómenos migratorios los van a hacer que asiente entre nosotros la idea de la multiculturalidad como una característica de nuestra sociedad, con una carga ambivalente en su percepción. Por un lado, se reconocen los aspectos positivos de la variedad de culturas, sobre todo si las consideramos propias o al menos cercanas, y por otro, tenemos una visión negativa, cargada de prejuicios y estereotipos, de la diversidad cultural que proviene de los gitanos o de latitudes del sur, especialmente de África.

Contamos, por tanto, en nuestro país, al igual que en la mayoría de las democracias occidentales con varias fuentes de multiculturalidad: varias minorías nacionales dentro de un Estado (andaluces, extremeños, vascos, catalanes, ...); grupos de inmigrantes de diferentes orígenes (africanos, americanos, asiáticos, ...); minorías étnicas de clara identidad [gitanos]. Además, si tenemos en cuenta las características comunes compartidas por varias personas, derivadas de sus implicaciones respecto a otros criterios de pertenencia a grupos (profesión, género, ...), nos encontramos con un amplio abanico de grupos diversos que conforman nuestra sociedad.

Para terminar con este apartado de aclaraciones terminológicas, vamos a realizar algunas precisiones sobre las diferencias y semejanzas entre multi e interculturalidad. En primer lugar, se produce un alto grado de sinonimia si tenemos en cuenta el origen geográfico y lingüístico de las aportaciones que estemos analizando. Así, en la mayoría de los trabajos de origen anglosajón se utiliza el término multicultural para denominar características y aspectos sociales y educativos muy similares a los que en el mundo latino se nombran con el adjetivo intercultural.

Centrándonos en este último, especialmente en los trabajos escritos en español, sí podemos apreciar varias diferencias entre el significado de ambos términos, relacionadas con las evidentes diferencias entre los prefijos. La multiculturalidad suele asociarse a la descripción de una característica de una determinada sociedad, grupo o incluso individuo, mientras que la interculturalidad se relaciona más con la integración de las aportaciones de los diferentes grupos y con sus relaciones interactivas. También se utilizan para señalar una diferencia de grado en las relaciones entre los grupos étnicos. La multiculturalidad haría referencia a unas relaciones de coexistencia o de situaciones de escasa convivencia, mientras que la interculturalidad serviría para caracterizar relaciones de convivencia avanzada, incluso de mestizaje. También se produce una diferencia cualitativa cuando hacemos referencia a la interculturalidad como valor hacia el que orientar las actuaciones que tengan como finalidad crear condiciones sociales y educativas favorecedoras de dicha convivencia. 
En el caso de la interculturalidad, además de la diferencia de grado que ya he señalado, se produce, a mi entender, un cambio cualitativo importante. No se trata sólo del establecimiento de contactos entre grupos y culturas, incluso de sus interacciones esporádicas, sino fundamentalmente de un continuado flujo de relaciones de intercambio que en determinados momentos pueden dar lugar a aportaciones culturales nuevas, distintas de las originarias de cada grupo y a la vez integradoras de ellas. Iríamos hacia la convivencia, siguiendo lo dicho con anterioridad.

En las relaciones interculturales no tiene por qué llegarse a un grado tan avanzado de interacción y de mestizaje que casi lleve a olvidar las características originales de cada grupo cultural antes de las relaciones con los demás grupos. No obstante, sí es cierto que se puede producir una cierta renuncia de algunas prácticas culturales al entrar en contacto con otros grupos.

Por otro lado, las relaciones entre los diferentes grupos culturales que interactúan en una relación de interculturalidad no se producen en un plano de igualdad, al menos inicialmente, ya que unos grupos pueden resultar más influyentes que otros, a pesar de contar con menor presencia cuantitativa.

En definitiva, podemos concluir este apartado reconociendo la complejidad de las relaciones entre los grupos étnicos y culturales, a la par que admitiendo la multiculturalidad como una característica evidente de las sociedades democráticas, incluso de los individuos que formamos parte de ellas, mientras que la interculturalidad supone un grado mayor de interacción entre los grupos.

\section{El papel de la educación ante la diversidad cultural}

Las instituciones escolares, especialmente su ubicación y sus relaciones con la comunidad educativa, juegan un papel decisivo en esas relaciones. Se vienen señalando cuatro modos de relación de las instituciones escolares con las realidades multiculturales en las que se insertan.

Cuando la relación es de asimilación, la cultura minoritaria se adapta, o intenta adaptarse, a la mayoritaria, que acepta a aquella en tanto que asume sus patrones culturales y sus principios educativos. La escuela que, como es lógico, se basa en los principios de la cultura mayoritaria, los incorpora a sus prácticas educativas sin tratamientos ni adaptaciones diferenciadas en función de la cultura de procedencia de los diferentes grupos, ni tiene en cuenta otras aportaciones que no sean las del grupo cultural que goce de la hegemonía. Otro tipo de relación está marcado por la diferenciación. En este caso, las instituciones escolares tratan de dar respuesta a las características culturales de los grupos minoritarios o menos poderosos presentes en la sociedad, ofreciéndoles posibilidades paralelas de escolarización. Se parte del reconocimiento de la coexistencia de los diferentes grupos étnicos y culturales y de sus respectivas instituciones escolares. Cada uno con su barrio y con su escuela, pero sin apenas relaciones de convivencia entre ellos. Se reconocen las aportaciones culturales de cada grupo, pero sin que lleguen a integrarse las de unos con las de otros en el currículo escolar. 
El principio de segregación subyacente en el caso anterior se intenta superan con el tipo de relación marcado por la integración. Ahora se parte del reconocimiento de los mismos derechos culturales y educativos para todos los grupos. Las instituciones escolares asumen un trato de igualdad para todos los alumnos, sin salir perjudicados o beneficiados en función de su procedencia social, ni su pertenencia a un grupo étnico y cultural. Todos asisten a todas las mismas escuelas y con los mismos profesores en aparente igualdad de condiciones. Del mismo modo, se intentan incorporar al currículo escolar las aportaciones más significativas y de mayor importancia educativa de los diferentes grupos culturales. Por último, entre las instituciones escolares y las sociedades multiculturales se puede llegar a establecer un tipo de relación en la que lo importante sea llegar conseguir que la educación adquiera todo su sentido y calidad y se desarrolle en igualdad para todos. En todos los procesos de planificación y de actuación educativa se debe asumir la diversidad cultural como riqueza, participándose institucionalmente de ella y procurando que de este enriquecimiento se beneficien todos los integrantes de todos los grupos culturales. En este caso, no sólo se integran las aportaciones culturales de los grupos con presencia directa en la comunidad educativa, sino todas aquellas que, aunque resulten lejanas en el espacio y el tiempo, puedan completar un currículo educativo de calidad, que. como hemos visto, llega a convertirse en sinónimo de currículo intercultural.

\section{Actuaciones educativas ante una fuente de diversidad cultural: las inmigraciones}

En las instituciones educativas tenemos que evitar el tratamiento estereotipado de las inmigraciones como fuente de diversidad étnica y cultural, superando generalizaciones que puedan dificultar el desarrollo de planteamientos educativos adecuados para todos los alumnos, sea cual sea su procedencia. Entre los inmigrantes existen evidentes diferencias derivadas de sus propios orígenes geopolíticos, que debemos tener en cuenta en los consiguientes tratamientos educativos, ya que van a influir en los comportamientos familiares y de los alumnos en relación con la actividad escolar. Los hijos de trabajadores cualificados oriundos de la Europa del Este no van a contar con las mismas necesidades educativas que los originarios de países africanos o de América Latina o de trabajadores no cualificados que vinieron a duras penas a Europa y que, al ir sobreviviendo y mejorando las condiciones de vida, han optado por reagruparse.

$\mathrm{Si}$ bien es cierto que en casi todos los casos, las primeras etapas de asentamiento de inmigrantes apenas conllevan reclamaciones respecto a la escolarización de sus hijos, ya que se conforman con sobrevivir y asimilarse a la cultura de las sociedades de acogida, es conveniente que en las acciones planteadas desde la educación intercultural vayamos analizando los matices y las diferencias que se dan dentro de la denominación genérica de inmigrantes para ir previendo las correspondientes intervenciones educativas.

Una de ellas, generalmente olvidada, es el desarrollo de programas de educación intercultural, tanto en el ámbito social como escolar, para todas las sociedades occidentales y, especialmente, con las poblaciones de acogida de inmigrantes. Una de las 
grandes ventajas que tiene la educación, si está bien planificada, es su labor preventiva, por ejemplo para evitar brotes racistas y xenófobos. Es importante trabajar educativamente con las sociedades de acogida para informarles sobre los motivos de los movimientos migratorios, el enriquecimiento que supone la diversidad cultural para todos, las ventajas para sus propios intereses, etc. Pensamos con bastante ingenuidad que el mero contacto va a favorecer los intercambios, sin crear situaciones problemáticas. Hace ya tiempo que Allport nos demostró que la hipótesis de contacto es insuficiente para superar estos prejuicios. Es necesario introducir variables de intervención educativa y social, como el trabajo colaborativo y la mejora de la autoestima, para que se pueda ir avanzando en las relaciones interculturales y favoreciendo que los conflictos que surjan se regulen de forma no violenta.

\section{Propuesta de un caso concreto: el plan para la atención educativa del alumnado inmigrante de la comunidad autónoma andaluza}

En esta línea, la Consejería de Educación y Ciencia de la Junta de Andalucía ha elaborado un Plan para la Atención Educativa al Alumnado Inmigrante que veremos a continuación, como una actuación en política educativa basada en los principios de la Educación Intercultural.

\subsection{Introducción}

Vivimos en una sociedad cada vez más plural, con una nueva dimensión internacional de la que surge la necesidad de educar para la solidaridad entre los pueblos.

La educación en los valores del respeto, la tolerancia activa y la solidaridad es el mejor instrumento para erradicar las actitudes de racismo y xenofobia que con cierta frecuencia se están presentado en las sociedades del llamado primer mundo como una reacción frente al fenómeno de la inmigración.

El reconocimiento de la diversidad cultural en los centros de enseñanza resulta fundamental para conseguir verdaderas sociedades interculturales. Los centros educativos tienen el deber de asegurar las bases para la igualdad real y efectiva en la escuela, el trabajo y la sociedad, atendiendo a la diversidad de género, etnia y cultura.

La educación tiene sin duda una función importante que desarrollar en el diálogo entre culturas, contribuyendo a derribar muros fraguados por la ignorancia, la incomprensión, la inseguridad y la falta de comunicación y solidaridad.

Para que la diversidad étnica y cultural se transforme en algo enriquecedor es preciso partir de un reconocimiento entre iguales, respetar la diversidad y promover el intercambio. Sólo así conseguiremos que el multiculturalismo se transforme en interculturalismo. Este es el reto.

La interculturalidad va más allá de la perspectiva multicultural porque, partiendo de la constatación y el reconocimiento del hecho de la diversidad cultural, sitúa la interacción cultural como un hecho educativo en sí mismo. La interculturalidad obliga a pen- 
sar en las relaciones culturales dentro de un proyecto educativo, pero también dentro de un proyecto social, que supone hacer posible la igualdad de derechos y de oportunidades entre los seres humanos que conviven en una sociedad determinada.

\section{El Centro Educativo, lugar privilegiado para una educación intercultural}

La interculturalidad supone, pues, pasar de poner el acento en la integración de la población inmigrante en la sociedad de acogida a pasar a poner el acento en una educación que se destina a la generalidad de la población y no sólo a las minorías nacionales 0 inmigrantes. Por tanto, no se concibe la educación intercultural como las actuaciones que hay que tener o realizar solamente con los miembros de uno de los grupos culturales en contacto, sino que supone enseñar a la ciudadanía a mirar a la otra persona con una óptica distinta para comprender cómo piensa y cómo siente y entender que desde la educación intercultural se obtiene un beneficio que afecta a todos los sujetos.

En este sentido, hablar de educación intercultural no supone hablar de un conjunto de objetivos y estrategias educativas que deban tenerse en cuenta exclusivamente en aquellos centros que escolarizan alumnado perteneciente a las minorías culturales, sino que uno de los objetivos fundamentales es conseguir que los miembros del grupo mayoritario acepten como iguales a los de los grupos minoritarios.

La educación intercultural consiste también en facilitar la igualdad de oportunidades para los miembros de las minorías culturales desfavorecidas. En este sentido la educación intercultural tiene aspectos compensadores y pone en marcha medidas y actuaciones dirigidas específicamente a los colectivos que presenta necesidades educativas especiales, entendidas éstas en sentido amplio, pero enmarcadas desde un nuevo modelo de escuela: la escuela intercultural.

Por ello, sólo volviéndose intercultural, el centro docente podrá poner en marcha un modelo educativo desde el que se inculque y fortalezca el deseo de conocer y dialogar con otras culturas y formas de vida, donde se eduque para ser capaz de ponerse en el lugar de la otra persona y entender que todo el mundo es respetable, huyendo de cualquier tipo de arrogancia cultural. En definitiva un modelo de centro que consiga que todos los miembros de la comunidad educativa desarrollen un compromiso personal en la defensa de la igualdad de los derechos humanos cívicos y políticos, y de rechazo a todo tipo de exclusión.

\subsection{Justificación}

El Plan se justifica porque el colectivo de hijos de inmigrantes presenta necesidades educativas a las que hay que dar respuesta especifica y se sustenta en la normativa que recoge el derecho y las finalidades de la educación así como en la que recoge el desarrollo de acciones de carácter compensador dirigida a los colectivos más desfavorecidos. De especial referencia para este Plan es la Ley $9 / 1999$, de 18 de noviembre, de Solidaridad en la Educación, que viene a consolidar y reforzar las medidas de compensación educativa iniciadas desde hace más de una década en la Comunidad Autónoma Andaluza. 
Necesidades que presenta el alumnado inmigrante

El alumnado hijo de inmigrantes, sobre todo el de origen africano, asiático o del este europeo, presenta tres características que hay que tener en cuenta a la hora de su escolarización. En primer lugar proceden de culturas diferentes a la andaluza; en segundo lugar, su lengua materna dispone de caracteres orales y escritos que distan bastante de la lengua española y, finalmente, son alumnos y alumnas que, en general, tienen necesidades educativas derivadas de situaciones de desigualdad en los ámbitos social y económico, sobre todo.

Una vez que se ha incorporado al centro de enseñanza, el alumnado hijo de inmigrantes se enfrenta a ciertos condicionantes para su plena inserción en el sistema educativo. El primero de ellos es el aprendizaje de la lengua vehicular de la enseñanza, si éste no se resuelve bien, se verá conducido al fracaso escolar. Pero se enfrenta también a otros condicionantes derivados de sus referentes culturales familiares, o de tener una lengua materna diferente de la que utiliza en el Centro Educativo.

Una mala resolución de las necesidades de este alumnado en el aprendizaje de la lengua de comunicación de la escuela, puede implicar, en muchos casos, la consolidación de déficits y retrasos escolares que no se acaban de superar nunca. Cuando una persona no habla el idioma escolar tiene problemas, no sólo en cuanto a sus resultados escolares, sino también en sus relaciones con sus compañeros y profesores, en definitiva, con todo el entorno escolar y social.

A la hora de analizar cuáles son las necesidades lingüísticas del alumnado inmigrante, hay que tener en cuenta que no se integra igual en el plano lingüístico, un niño o niña de Educación Infantil, que el que se incorpora tardíamente en los últimos cursos de Educación Primaria o en Educación Secundaria. En el primer caso, la inmersión directa en el aula puede ser un procedimiento adecuado. En el segundo caso, son necesarias otras medidas que faciliten el aprendizaje de la lengua lo antes posible, además de medidas complementarias de apoyo y medios adecuados de compensación.

Por otro lado, los alumnos y las alumnas de familias inmigradas, insertados en el sistema educativo, disponen de distintos referentes culturales, unos procedentes de su entorno familiar y otros procedentes de su entorno escolar. En tales casos es importante que no se produzca una fuerte disgregación de esos referentes. Para ello deben percibir que a su lengua y a su cultura de origen se le da la importancia que merece, y, además, les conviene tener un buen aprendizaje de la misma para acceder a una mejor comprensión de las pautas culturales de su entorno familiar.

El alumnado inmigrante debe acceder al proceso formativo de tal forma que la variedad de referentes culturales no le produzca distorsión en su educación y pueda desarrollar en libertad sus propias pautas culturales. En ese sentido, es necesario que los centros docentes que escolaricen alumnado perteneciente a minorías étnicas establezcan en sus proyectos de centro las actuaciones necesarias para facilitar el tratamiento de las diferentes culturas en un plano de igualdad y para potenciar la integración social y la capacidad del alumnado para aprender a convivir en contextos cultu- 
Fundamentos legales

La Constitución Española en su artículo 27.2 recoge que "la educación tendrá por objeto el pleno desarrollo de la personalidad humana en el respeto a los principios democráticos de convivencia y a los derechos y libertades fundamentales".

Por otra parte, el art. 2.1. de la LODE, especifica los fines de la actividad educativa: formación en el respeto de los derechos y libertades fundamentales y en el ejercicio de la tolerancia y de la libertad dentro de los principios democráticos de convivencia; preparación para participar activamente en la vida social y cultural; formación para la paz, la cooperación y la solidaridad de los pueblos. En los mismos términos se establece en la LOGSE en su artículo 1 las finalidades de la educación.

Igualmente, en su artículo 63 especifica que "con el fin de hacer efectivo el principio de igualdad en el ejercicio del derecho a la educación, los poderes públicos desarrollarán las acciones de carácter compensatorio en relación con las personas, grupos y ámbitos territoriales que se encuentren en una situación desfavorable y proveerán los recursos económicos para ello"

La Conferencia General de la Organización de las Naciones Unidas para la Educación, las Ciencias y la Cultura, proclamó la Declaración de los Principios de Cooperación Cultural Internacional, cuyo primer artículo recoge: "Cada cultura tiene una dignidad y un valor que han de ser respetados y conservados. Todas las personas tienen el derecho y el deber de desarrollar su cultura. En su rica variedad y diversidad y en las reciprocas influencias que ejercen unas sobre otras, todas las culturas forman parte del patrimonio común perteneciente a toda la humanidad".

La Ley 9/1999 de 18 de noviembre de Solidaridad en la Educación recoge entre sus objetivos potenciar el valor de la interculturalidad, integrando en el hecho educativo la riqueza que supone el conocimiento y respeto por la cultura de los grupos minoritarios así como desarrollar actitudes de comunicación y respeto entre todos los miembros de la comunidad educativa, independientemente de sus capacidades personales y de su situación social o cultural.

La misma Ley, en su artículo 17, dice que "los centros con alumnado perteneciente a la comunidad gitana andaluza, minorías étnicas o culturales o inmigrantes incluyan en sus proyectos de Centro medidas que favorezcan el desarrollo y el respeto de la identidad cultural de este alumnado, que fomente la convivencia y que faciliten su participación en el entorno social"

\subsection{Objetivos del plan}

La Consejería de Educación y Ciencia con el Plan para la Atención Educativa al Alumnado Inmigrante pretende su integración desde la perspectiva de un enriquecimiento mutuo de las culturas mayoritarias y minoritarias como principio básico de la interculturalidad y desde la convicción de que el Centro Educativo es el medio idóneo para enseñar a convivir desde la práctica de valores como el respeto, la tolerancia y la solidaridad.

En este sentido, educar conjuntamente a personas de diferentes culturas implica trabajar para conseguir un espacio cultural común que no suponga pérdidas de identidad sino enriquecimiento de ésta y apertura mental y vital a lo diferente. Sin embargo, aceptar la 
riqueza de otras sociedades, no implica que no haya unos límites. Cuando en los aspectos culturales se encuentre la negación de los derechos básicos universales de mujeres y de hombres, de niñas y de niños, habrá que desarrollar una dimensión crítica que posibilite el derecho y la libertad a discrepar y abandonar parte de la propia cultura.

Esta finalidad se concreta en los siguientes objetivos:

1. Facilitar la escolarización de todas las niñas y niños pertenecientes a familias inmigrantes, en los mismos términos que el alumnado andaluz.

2. Favorecer que los centros elaboren Proyectos Educativos interculturales que faciliten y promuevan procesos de intercambio, interacción y cooperación entre las culturas.

3. Potenciar programas de apoyo para el aprendizaje de la lengua española.

4. Facilitar el aprendizaje de la lengua materna del alumnado para que éste no pierda la conexión con su cultura de origen.

5. Favorecer un clima social de convivencia, respeto y tolerancia, en especial en las zonas que acogen inmigrantes, fomentando que los centros educativos sean un núcleo de encuentro y difusión de los valores democráticos no sólo de la comunidad educativa sino del propio barrio.

6. Potenciar el desarrollo de acciones de formación integral del alumnado inmigrante adulto, incidiendo de forma particular sobre los padres y madres que han inmigrado y cuyas hijas e hijos están escolarizados en la educación básica.

Impulsar Planes de Integración Social de la población inmigrante más desfavorecida con la participación de las distintas

\subsection{Medidas y actuaciones}

Las medidas y actuaciones del Plan van encaminadas a garantizar la atención educativa del alumnado hijo de inmigrante en las mismas condiciones de calidad que la atención educativa a las niñas y niños andaluces, así como a favorecer en la comunidad educativa el desarrollo de actitudes de respeto a la diversidad étnica y cultural, así como el aprecio a los diferentes valores y costumbres de otras culturas, desde el análisis crítico tanto de éstas como de la autóctona mayoritaria.

\section{Primer objetivo}

Facilitar la escolarización todas las niñas y niños pertenecientes a familias inmigrantes, en las mismas condiciones que el alumnado andaluz

La Consejería de Educación y Ciencia velará para que el proceso de escolarización del alumnado inmigrante se realice en los mismos términos y en las mismas condiciones de igualdad que la escolarización del alumnado español. Para ello, se dictarán instrucciones expresas para evitar cualquier actuación que discrimine o limite la escolarización del alumnado extranjero. 


\section{Medidas}

1.1 Divulgación, entre las familias y colectivos de inmigrantes, de los aspectos básicos del proceso de escolarización y organización del sistema educativo en Andalucía y de las convocatorias de becas y ayudas a estudio.

Es necesario que la población inmigrante esté informada de la organización del Sistema Educativo y de cómo se realiza el proceso de escolarización: documentación necesaria, plazos de inscripción y matriculación. Para ello, la Consejería de Educación y Ciencia publicará folletos divulgativos, en español y en los diferentes idiomas de las personas inmigradas, de forma que puedan acceder fácilmente a la información. En esta medida, podrán colaborar las Asociaciones de Madres y Padres de alumnos, los servicios de orientación e información de la administración educativa y de los ayuntamientos y las Asociaciones sin ánimo de lucro, entre otros.

1.2 Campañas de sensibilización entre la población inmigrante para la escolarización de las niñas y niños en la Etapa de Educación Infantil.

Dada la importancia de la atención educativa en los primeros años, se realizarán campañas de sensibilización entre las familias inmigrantes para que soliciten la escolarización en el segundo ciclo de Educación Infantil, sobre todo del alumnado perteneciente a familias desfavorecidas, haciendo especial hincapié en la escolarización de las niñas, con objeto de compensar determinadas carencias para que este alumnado pueda acceder en igualdad de condiciones a la enseñanza obligatoria.

1.3 Dotación de recursos humanos y materiales extraordinarios a los centros que escolaricen un número significativo de alumnado inmigrante.

El alumnado inmigrante, sobre todo el de incorporación tardía al sistema escolar (hecho que se ha incrementado bastante en los últimos años por el desarrollo de la reagrupación familiar\}, suele tener dificultades para seguir con normalidad el proceso de enseñanza-aprendizaje. Esta situación puede tener incidencias educativas cuando hay en el aula o en el ciclo un número significativo de alumnos

y alumnas. Por ello, se dotará a los centros que escolaricen a un número significativo de alumnado inmigrante que requiera medidas de compensación educativa para su integración en el sistema educativo, de profesorado de apoyo para que este alumnado pueda superar las dificultades de partida y acceder a la educación en las mismas condiciones que sus compañeros. Igualmente, estos centros se considerarán prioritarios para la implantación de las medidas relativas a la mejora de las plantillas de los centros, contenidas en el “Acuerdo por la Educación” (Cupo 13-23-33).

1.4 Acceso a los servicios complementarios.

Para favorecer el acceso a la escolarización obligatoria del alumnado perteneciente a minorías étnicas y culturales proveniente de núcleos de población aislados y cuyas familias se encuentren en situación económica desfavorecida, la Consejería de Educación y Ciencia facilitará los servicios complementarios de comedor, transporte y, en su caso, residencia, conforme a las condiciones que en las convocatorias anuales de ayudas para estos servicios se establezcan. 
El comedor escolar puede ser un espacio privilegiado para conocer los aspectos culturales relacionados con las distintas formas de selección y preparación de los alimentos, así como para analizar los esquemas previos de niños y niñas sobre la división de los roles e intentar la no reproducción de la división de funciones según modelos estereotipados. A través de las tareas que implica el acto de la comida, el alumnado puede adquirir habilidades para satisfacer de forma autónoma las necesidades personales y las necesidades de las personas con las que se convive y entender que es una responsabilidad tanto de las alumnas como de los alumnos.

1.5. Acceso a plazas en las Residencias Escolares para que el alumnado inmigrante pueda continuar sus estudios después de cursar las enseñanzas obligatorias.

Es deseable que el alumnado inmigrante continúe sus estudios de Bachillerato o de Formación Profesional, después de acabar la enseñanza obligatoria, para que esté capacitado para acceder al mundo laboral cualificado. Por ello, se le facilitará, en el caso de que sea necesario, plazas en las Residencias Escolares de la Consejería de Educación y Ciencia, en las mismas condiciones que las establecidas con carácter general para todo el alumnado en la correspondiente convocatoria pública.

Dado que, en la cultura de la mayor parte de las familias inmigrantes, no se potencia que las adolescentes accedan a estudios postobligatorios, la Consejería de Educación y Ciencia considera necesario ofertar, de manera especifica para las alumnas, plazas en estas residencias.

\subsection{Fomento de la participación del alumnado}

inmigrante en las actividades extraescolares del centro.

Es necesario que el alumnado inmigrante participe en las actividades extraescolares culturales y deportivas que organicen los centros docentes para que puedan tener la oportunidad de realizarse personalmente y de participar en distintos ámbitos de la vida social. En este sentido, se apoyarán los proyectos e iniciativas de los centros que expresamente incluyan la participación del alumnado inmigrante, presentadas al amparo de las convocatorias para la realización de actividades extraescolares que las Delegaciones Provinciales harán públicas para cada curso escolar.

\subsection{Formalización de convenios con entidades}

sin ánimo de lucro para establecer la figura mediadora intercultural.

La Consejería de Educación y Ciencia, en colaboración con la Consejería de Asuntos Sociales, formalizará convenios de colaboración con asociaciones sin ánimo de lucro y organizaciones no gubernamentales, para desarrollar actividades de compensación educativa con el alumnado y las familias, contando con la colaboración de un mediador o mediadora intercultural, cuando se considere necesario, que favorezca el acercamiento del alumnado y su familia a la institución escolar y a los servicios y ayudas de que dispone el Sistema Educativo. 


\section{Segundo objetivo}

Favorecer que los centros elaboren Proyectos de Centro interculturales que faciliten y promuevan procesos de intercambio, interacción y cooperación entre las culturas.

Facilitar la educación intercultural implica, por parte de los centros, una revisión del Proyecto Educativo que se está llevando a cabo, ya que la educación intercultural afecta a toda la comunidad educativa. Se trata de tomar conciencia del estado de la cuestión en el centro, tanto en un sentido cuantitativo (número y proporción de la composición multicultural) cuanto en una perspectiva cualitativa (percepción, valoración, tipo de relaciones que se producen).

La educación intercultural debe impregnar todos y cada uno de los elementos del Proyecto de Centro reconociendo la riqueza que supone la diversidad cultural. Un Proyecto de Centro tiene que estar asentado en el principio de la diferencia como enriquecimiento para todos y en la consideración de la interculturalidad como un proceso de comunicación e intercambio.

El Proyecto Curricular de Centro debe reflejar un currículo integrador, que recoja la experiencia y las necesidades no sólo de los alumnos de las diferentes culturas sino. también, y en la misma medida la experiencia y necesidades de las alumnas y que incluya la contribución histórica de las mujeres, tanto de la cultura mayoritaria, como de las minoritarias, al desarrollo económico, social y cultural de la humanidad. Desde el proyecto curricular se pretende desarrollar una competencia en los alumnos y alumnas que posibilite entender el mundo desde diferentes lecturas culturales, reflexionar críticamente sobre la propia cultura y la de los demás y generar una actitud y vivencia positiva, comprometida, enriquecedora de las relaciones entre las culturas

Dentro del Proyecto Curricular tiene especial relevancia el Plan de Orientación y Acción Tutorial ya que es el instrumento que va a permitir a los equipos docentes incluir los programas de acogida y las actuaciones específicas para favorecer el proceso de integración del alumnado perteneciente a minorías étnicas, así como las medidas que contribuyan a evitar las actitudes de rechazo, intolerancia o discriminación. Los tutores y tutoras son las personas indicadas para prestar especial atención al control del absentismo escolar, sobre todo en las niñas, ya que las familias tienden más a enviar al centro educativo a los niños que a las niñas. Es importante, dada la cultura de origen de la mayoría de las familias inmigrantes, potenciar de manera especial que las alumnas participen de forma activa, tanto en las actividades del aula, como en las actividades generales del centro, desde la toma de conciencia de la igualdad de derechos y oportunidades respecto a los alumnos.

Uno de los objetivos de la acción tutorial es proporcionar al alumnado y a sus familias una información y orientación escolar sin las limitaciones que imponen las expectativas de sexo/género y presentar las profesiones y carreras rompiendo los estereotipos con la colaboración de hombres y mujeres que no siguen los modelos tradicionales.

El Reglamento de Organización y Funcionamiento es el instrumento que recoge medidas concretas para la consecución del clima idóneo de convivencia que garan- 
tice el respeto y la tolerancia a las minorías, evitando, además, mensajes que puedan inducir a las alumnas y alumnos a adaptarse a los estereotipos de género. También se deben incorporar en él medidas para que en las publicaciones escolares y material didáctico, en los tablones de anuncios y en los carteles estén reflejados de manera equilibrada, tanto en los textos como en las imágenes, las diferentes etnias, sexos, religiones, sin estereotipos de género y sin prejuicios ni discriminación hacia las diferentes culturas.

Un Proyecto de Centro Intercultural se concreta en el marco del aula, en primer lugar creando un marco de aprendizaje que se apoye en los referentes culturales que aportan las alumnas y los alumnos. Sólo así se puede evitar que el alumnado genere una yuxtaposición de términos y de códigos, aquellos que se utilizan para afrontar los problemas de la vida cotidiana y los que se utiliza para resolver los trabajos en el ámbito escolar.

En segundo lugar, y simultáneamente, estimulando que los distintos referentes culturales confluyan e interactúen. Es necesario un marco de relaciones donde sea verdadera la comunicación y la interacción, donde sea posible la expresión espontánea de la propia identidad cultural, donde esta expresión se legitime, se valore y se analice críticamente, donde se ponderen los valores ideológicos que influyen en la percepción de las culturas, donde en definitiva sea posible construir la propia identidad cultural de manera enriquecedora, adquiriendo al mismo tiempo competencia para tener conciencia de los esquemas culturales que se tienen alrededor.

\section{Medidas}

2.1 Formación y asesoramiento específico al profesorado de los centros que atienden al alumnado perteneciente a familias inmigrantes.

El profesorado de los centros que atiende alumnado perteneciente a minorías étnicas debe recibir una formación específica que le facilite la elaboración proyectos de Centro interculturales y el conocimiento y comprensión de las pautas y referentes culturales tanto de las alumnas como de los alumnos que reciben.

Para ello se incluirán en el Programa bianual 2000-01 de formación del profesorado todas las acciones formativas necesarias para atender a dicho colectivo de profesores y profesoras. Asi mismo, se considera oportuno que los centros aludidos desarrollen su propio plan de formación en centro para ajustarse mejor a sus necesidades. Para ello, los Centros de Profesorado pondrán a su disposición los recursos necesarios.

2.2. Publicación de materiales de apoyo y asesoramiento para los centros y el profesorado.

La Consejería de Educación y Ciencia elaborará y publicará materiales curriculares de educación intercultural que sirvan de apoyo y asesoramiento al profesorado que atiende educativamente a alumnado perteneciente a minorías étnicas. 


\section{Tercer objetivo}

Potenciar programas de apoyo para el aprendizaje de la lengua española.

Una de las prioridades de este colectivo es la necesidad del aprendizaje de la lengua española lo más rápidamente posible, con objeto de poder integrarse en el ámbito escolar y social y poder acceder al aprendizaje escolar.

En la adquisición de la lengua de acogida hay que tener presente que aprender un lenguaje es aprender un mundo de significados culturales vinculados a un conjunto de significantes, y con tales significados, los modos en que las personas de su entorno entienden e interpretan la realidad. El lenguaje contribuye así a construir una representación del mundo socialmente compartido y comunicable en el entorno sociocultural.

En este sentido, resulta necesario tener en cuenta algunos aspectos concretos, como el papel de la ideología sexo/género en la construcción y uso de la lengua y sus implicaciones sociales; el lenguaje no sexista como instrumento para el cambio de actitudes, valores y normas; el sexismo en los sistemas de comunicación verbal y no verbal. Estos aspectos potenciarán el uso no discriminatorio del lenguaje.

\section{Medidas}

3.1 Creación de aulas temporales de adaptación lingüística.

Una de las dificultades iniciales del alumnado inmigrante para su integración en el sistema educativo es el desconocimiento del idioma y de las pautas de comportamiento e interrelación existentes en los centros escolares, bastante alejados en sus formas de organización y funcionamiento de los referentes culturales propios de este alumnado. Por este motivo, parece aconsejable, en determinados casos, un periodo de adaptación y acogida centrado en el aprendizaje del español y de las pautas de conducta propias de la institución escolar. Para ello se crearán aulas temporales de adaptación lingüística con objeto de facilitar la incorporación al sistema educativo en los momentos iniciales, incrementando el número de estas aulas ya existente.

Estas aulas deben tener unas características básicas que no conviene perder de vista. En primer lugar, el paso del alumnado inmigrante por ellas será transitorio, limitándose al tiempo estrictamente necesario para un desenvolvimiento mínimo en lenguaje oral en español, así como para interpretar adecuadamente la vida del colegio y el entorno en el que va a vivir: horarios, funcionamiento de diferentes servicios de centros como comedor escolar, actividades extraescolares, etc. Otro aspecto básico de esta experiencia consiste en la coordinación con el colegio en el que el alumno o alumna ya esté matriculado antes de pasar temporalmente a esta aula. Dicha coordinación es necesaria a la llegada al aula, durante y después para orientar al que va a ser su tutor o tutora y Equipo Docente. También se distinguen estas aulas por la heterogeneidad del alumnado en edades, sexo, país de procedencia, etc. y por la individualización de la enseñanza que en ellas se imparte, basada en las características de cada alumna y alumno. Una última característica consiste en la estrecha colaboración con la familia que en todo momento se trata de asegurar. 
3.2 Formalización de convenios con entidades sin ánimo de lucro para apoyar el aprendizaje de la lengua de acogida, con personal cualificado que conozca la lengua propia del alumnado.

Es deseable que en el apoyo del aprendizaje de la lengua intervenga personal cualificado que provenga del colectivo de inmigrantes o que conozca la lengua propia del alumnado para que pueda haber un reconocimiento de aquello que el escolar lleva a la escuela. Pero además esta figura garantiza el contacto social y comunicativo entre el profesorado y el alumnado. Esta persona, como el resto del profesorado, siempre utilizará la lengua castellana, pero podrá entender al alumnado cuando éste utilice su propia lengua. En este sentido, la Consejería de Educación y Ciencia como complemento a la medida señalada en el punto anterior, o en aquellos centros donde el número de alumnado inmigrante sea reducido, formalizará convenios con aquellas entidades y asociaciones sin ánimo de lucro que puedan facilitar personas bilingües que ayuden al alumnado inmigrante en el proceso de integración y aprendizaje de la lengua española.

\section{Cuarto objetivo}

Facilitar el aprendizaje de la lengua materna para

que el alumnado no pierda su cultura de origen.

La Consejería de Educación y Ciencia es consciente de la necesidad de impulsar acciones encaminadas a favorecer al aprendizaje de la lengua materna del alumnado inmigrante. con objeto de que pueda adquirir una mayor conciencia lingüística y acceder a una mejor comprensión de las pautas de su extracción sociocultural de origen. Por otra parte entre el dominio de la lengua propia y el aprendizaje de una segunda lengua existe una unidad, de forma que un buen aprendizaje de la lengua propia y su valoración por el otro conlleva una mejor disposición y habilidades para el aprendizaje de la nueva lengua.

Por eso es importante, que en el caso del alumnado inmigrante, el profesorado se esfuerce en transcribir aprender y utilizar adecuadamente sus nombres, formas de saludar etc. Es decir, que cada alumno y alumna se sienta apreciado y valorado en aquello que es suyo y aporta a la comunidad.

\section{Medidas}

4.1 Apoyo a programas para el aprendizaje y desarrollo de la lengua y cultura maternas.

Se realizarán convenios con entidades que ofrezcan estos aprendizajes y que puedan desarrollarlos dentro del marco escolar, aunque fuera del horario lectivo.

4.2. Elaboración de materiales didácticos para la enseñanza de la lengua materna del alumnado inmigrante.

Los materiales didácticos son un recurso importante para que el profesorado pueda llevar a cabo su quehacer educativo. En este sentido, es necesario elaborar materiales específicos para la enseñanza de la lengua materna del alumnado y hacerlos llegar a los centros para facilitar este proceso de enseñanza. 
4.3 Gestión ante los países de origen para que faciliten profesorado para que el alumnado hijo de inmigrante tengan un buen dominio de su lengua materna y para que el resto del alumnado del centro tenga opción de aprenderlas.

El respeto y la valoración y la enseñanza de la propia lengua son elementos decisivos para que la inmigración se incorpore a la lengua de la escuela. Cuando esta enseñanza se realiza por profesorado del país de origen se introduce un elemento de calidad. Por ello la Consejería de Educación y Ciencia, en el marco de los convenios de cooperación con las autoridades de los países de origen que puedan formalizarse, favorecerá la presencia en los centros docentes de profesorado facilitado por las autoridades correspondientes.

\section{Quinto objetivo}

Favorecer un clima social de convivencia, respeto y tolerancia, en especial en las zonas que acogen inmigrantes, fomentando que los centros educativos sean un núcleo de encuentro y difusión de los valores democráticos no sólo de la comunidad educativa sino del propio barrio.

La integración de toda la población en los ámbitos escolar y extraescolar tiene que basarse en el derecho de todos a vivir en una sociedad que no fragmente entre inmigrantes y autóctonos, sino hacia una sociedad formada por ciudadanas y ciudadanos con los mismos derechos y con capacidad para reconocerse en los universales, de forma que la diversidad de orígenes, de capacidades y de características sociales y culturales sea reconocida como un elemento común de toda la población.

\section{Medidas}

5.1. Apoyo a los centros para que pongan en marcha procesos de reflexión y contraste sobre la perspectiva intercultural que impliquen a todos los sectores del barrio en el que se encuentra el centro.

Los centros educativos son un lugar idóneo para analizar de forma objetiva y responsable los fenómenos migratorios y para potenciar la empatía social y cultural hacia los otros desde la creencia de que todos los seres humanos nacen libres e iguales en dignidad y derechos.

\subsection{Impulso de la participación de Madres y Padres} del alumnado inmigrante en los centros docentes.

La Consejería de Educación y Ciencia potenciará que los centros educativos, situados en zonas donde la presencia de esta población es significativa, fomenten la participación de las madres y padres perteneciente a estas minorías en las Asociaciones de Madres y Padres de Alumnos y en la vida del centro, organizando campañas informativas, jornadas interculturales y actividades culturales diversas. En este sentido, la Consejería convocará ayudas para financiar actividades de federaciones y confederaciones de asociaciones de padres y madres de alumnos, con el objetivo de promover su participación, apoyar su formación, propiciar un mejor conocimiento del sistema educativo y potenciar su implicación para favorecer la convivencia en los centros. 
5.3 Fomento de la participación del alumnado inmigrante en las Asociaciones de Alumnos y Alumnas.

Para facilitar el proceso de integración en el centro, es importante potenciar que el alumnado inmigrante participe en las organizaciones estudiantiles, de tal forma, que se sienta informado y asesorado y pueda participar en la vida del centro en un plano de igualdad. La Consejería de Educación y Ciencia convocará anualmente ayudas para financiar actividades de las organizaciones estudiantiles andaluzas. En dichas convocatorias se apoyarán los proyectos que expresamente contemplen la participación del alumnado inmigrante en las asociaciones de alumnos y alumnas.

\section{Sexto objetivo}

Potenciar el desarrollo de acciones de formación integral de los alumnos y alumnas inmigrantes adultos, interviniendo de forma especial sobre los padres y madres cuyas hijas e hijos estén escolarizados en la educación básica.

\section{Medidas}

6.1 Integración de la población inmigrante en la formación básica de Adultos.

La Consejería de Educación y Ciencia favorecerá la inscripción en los centros de Educación de las Personas Adultas de la población inmigrante para que tenga acceso a los niveles de formación básica de adultos. En particular, se realizarán campañas informativas para que las mujeres inmigrantes se interesen en acceder a esta formación, dada su importancia para una efectiva integración social y laboral.

6.2. Desarrollo de planes educativos en los

Centros de Adultos dirigidos a la población inmigrante.

La Consejería de Educación y Ciencia considera necesario favorecer el desarrollo de programas educativos destinados al intercambio cultural y planes de animación sociocultural que faciliten un mejor conocimiento de las diversas culturas. En este sentido, se desarrollarán planes educativos al amparo del artículo $4^{\circ}$ de la Ley $3 / 1990$, para la Educación de Adultos en Andalucía, dirigidos a mejorar la convivencia, el conocimiento y el respeto de la diversidad cultural.

6.3. Formación especifica del profesorado de Educación de las Personas Adultas que trabaje con población inmigrante.

La necesidad de conocer los valores de las otras culturas y desarrollar una actitud favorable en este sentido, es básico para trabajar con personas inmigrantes adultas. El valor, el momento, el lugar, la amplitud de lo que hay que guardar en secreto, los temas que pueden ser motivo de conversación y los que no, son aspectos vivenciales muy específicos de cada cultura.

El valor y la importancia del espacio, de su ordenamiento, de su funcionalidad son diferentes en cada cultura. Incluso la distancia óptima para establecer un diálogo interper- 
sonal. También el concepto del tiempo, la forma de medirlo, el valor de la puntualidad, o su aprovechamiento son diferentes. Si cada cultura organiza su tiempo en función de sus necesidades, de sus ritos, su religión. es importante que el profesorado conozca estos datos y actúe en consecuencia. En este sentido, se pueden hacer adaptaciones específicas del horario escolar para que el alumnado musulmán que lo desee pueda practicar el ayuno durante el mes del Ramadán.

El profesorado necesita tener el máximo de información respecto a la cultura de su alumnado, tanto en los aspectos que concierne a los hombres, como en los que concierne a las mujeres, ya que éstas se encuentran en situación de desigualdad y, en muchos casos, en situación de negación de los derechos básicos, para poder desarrollar y facilitar al máximo su capacidad para escoger, a la vista de las posibilidades existentes, su itinerario de desarrollo personal, formativo, laboral y social.

Para ello se incluirán en los Programas de Formación del Profesorado acciones formativas que atiendan las necesidades de formación en este ámbito. Así mismo, se favorecerá que estos centros, con el apoyo del Centro de Profesorado que corresponda, desarrollen su propio plan de formación en centro para ajustarse mejor a sus necesidades.

6.4 Establecimientos de convenios con asociaciones.

organizaciones o instituciones que trabajen con población inmigrante.

El trabajo conjunto entre la Consejería de Educación y las asociaciones sin ánimo de lucro que trabajan con la población inmigrante va a suponer favorecer el intercambio de experiencias, asi como el intercambio de materiales que favorezcan una mejor formación, tanto en el aprendizaje de la lengua, como de las vías de participación social. Este trabajo conjunto permitirá poner a disposición del alumnado inmigrante las herramientas básicas que le permitan comprender y analizar el conjunto de situaciones y procesos en que está implicado en su nuevo entorno cultural.

6.5 Promoción de la participación de las personas inmigrantes adultas en asociaciones de alumnos y alumnas, de vecinos, culturales etc.

Es necesario que la población inmigrante, como ciudadanos y ciudadanas, se sienta miembro de los colectivos sociales para facilitarle una mayor integración. La educación de las personas inmigrantes adultas ha de ser una educación comprometida con los proyectos de la comunidad y por ello se le debe facilitar los recursos necesarios para el análisis y participación de las diversas formas de organización y participación social. Con esta finalidad, desde los Centros de Educación de Adultos se divulgará entre la población inmigrante la existencia y características de las asociaciones de diferente tipo que operen en el entorno y fomentarán la participación de la población inmigrante en las mismas.

6.6 Impulsar Planes de Acción Comunitaria que permitan el desarrollo de acciones de integración social.

La Consejería de Educación seguirá potenciando acuerdos con los Ayuntamientos para desarrollar programas comunitarios de integración social de las personas inmigrantes adultas. 
Séptimo objetivo

Impulsar Planes de Integración Social de la población inmigrante más desfavorecida con la participación de las distintas administraciones.

La propuesta de una sociedad intercultural no se reduce al ámbito educativo y menos, todavía, a la institución escolar. La estructura de las relaciones entre mayorías y minorías sociales está atravesada por otros ejes como la dinámica socioeconómica, las políticas estatales de inmigración, ciudadanía y pluralismo cultural, así como las actitudes y comportamientos de la población autóctona y las estrategias de los propios colectivos de inmigrantes en cuanto actores sociales. La propuesta de la interculturalidad representa un reto para todas las instituciones socialesy para todas las administraciones públicas. Por tanto, la labor del centro educativo tiene que verse reforzada por actuaciones en el ámbito sociocomunitario de otras instituciones y administraciones.

4.5. Seguimiento y evaluación del plan para la atención educativa al alumnado inmigrante

Se establecerá una comisión de seguimiento integrada por representantes de las diferentes Direcciones Generales de la Consejería de Educación y Ciencia y cuya presidencia ostentará el Director General de Orientación Educativa y Solidaridad o persona en quien delegue.

Asimismo se establecerá una Comisión Técnica compuesta por la Dirección General de Orientación Educativa y Solidaridad y por el Coordinador o Coordinadora Provincial del Area de Compensación Educativa y por el inspector o Inspectora del Area de Atención a la Diversidad de cada una de las Delegaciones Provinciales.

La Consejería de Educación y Ciencia establecerá un procedimiento para la evaluación de las medidas y actuaciones del Plan. Esta evaluación se realizará en colaboración con los centros implicados. 